\title{
A Quasi-experimental Study to Assess the Effect of Planned Teaching Programme on Knowledge and Practice Regarding Management of Patient with Intra-Aortic Balloon Pump among Staff Nurses Working in Intensive Care Unit of Selected Hospital
}

\author{
Shweta Rasaria', Suchita Sawant ${ }^{2}$ \\ ${ }^{1}$ Department of Child Health Nursing, Bombay Hospital College of Nursing, Mumbai, Maharashtra, India, ${ }^{2}$ Department of Medical-Surgical Nursing, Bombay Hospital \\ College of Nursing, Mumbai, Maharashtra, India
}

\section{Abstract}

Background: Coronary artery serves as a fuel pipelines to the heart muscles. Impaired left ventricular function causes low cardiac output and inadequate coronary artery perfusion. About 45 million of Indian people are affected with coronary artery diseases. Intra-aortic balloon pump (IABP) is considered as the first hemodynamic support device to help in improvements in the myocardial oxygen supply/demand ratio and circulatory support. Nursing care involves the care of the pump as well as assessing the patient from a cardiovascular and hemodynamic perspective. There was no specific study conducted to assess and improves the knowledge and practice of staff nurses regarding the management of a patient with IABP, particularly in that area considered important by the researcher.

Aim: Thus, a quasi-experimental study was designed to assess the effect of planned teaching programme on knowledge and practice regarding the management of a patient with IABP among staff nurses working in intensive care unit (ICU) of the selected hospital.

Methodology: The study was conducted in a multispecialty hospital. This study included 50 staff nurses working in ICU, who meet the inclusion criteria listed by the researcher. The sampling technique used in this study was non-probability convenient sampling. Based on the objectives of the study, a structured knowledge questionnaire and self-reported checklist based on the practice were prepared to evaluate the knowledge and practice of staff nurses before and after planned teaching programme.

Results: The knowledge and practice level of staff nurses in the posttest was significantly increased than the pretest score. The calculated $t$-value was found to be 31.76 for knowledge and it was greater than the table $t$-value 2.01 at 0.05 level and for practice the calculated $t$-value was found to be 27.77, which was greater than the table $t$-value 2.01 at 0.05 level of significance.

Conclusion: Thus, the findings of the study proved that teaching through planned teaching programme method was effective to improve the knowledge and practice of the staff nurses.

Keywords: Cardiac disease patients, intra-aortic balloon pump, nurses, teaching plan

\section{INTRODUCTION}

Coronary artery serves as a fuel pipelines to the heart muscles. Patient with one or more risk factors for coronary artery disease is

\begin{tabular}{|l|}
\hline \multicolumn{1}{|c|}{ Access this article online } \\
\hline Website: http://innovationalpublishers.com/Journal/ijnmi \\
\hline ISSN No: $2656-4656$ \\
DOI: $10.31690 /$ ijnmi/46 \\
\hline
\end{tabular}

susceptible to the increased buildup of material begins to encroach on the inner channel and starts to interfere with the free flow of blood through the coronary artery. According to the American Heart Association, coronary artery disease caused one of every six deaths in the United States. It estimates that 1.2 million Americans will have a myocardial infarction annually and about one-fourth of these will die in an emergency department or before reaching the hospital. One in 9 death certificates in the United States mentioned heart failure, and $>2200$ Americans die of the coronary vascular disease each day. ${ }^{[1]}$ 
Intra-aortic balloon pump (IABP) is considered as the first hemodynamic support device to help in improvements in the myocardial oxygen supply/demand ratio and circulatory support. Since then, it has assumed a pivotal role in the treatment of those with heart failure and myocardial ischemia and is the most widely used mechanical support. IABP is a valuable option in cardiac surgeries and end-stage cardiac diseases; patients are prone to many complications due to IABP therapy. This device may be used in patients with a wide range of disorders that cause low cardiac output or cardiac instability, such as refractory angina, ventricular dysrhythmias associated with ischemia, pump failure caused by cardiogenic shock, and intraoperative myocardial infarction or low cardiac output after bypass surgery. ${ }^{[2]}$ Today more than 160,000 patients worldwide receive this therapy annually.

A retrospective cohort study was conducted to describe the contemporary utilization, clinical outcomes and complication rates of IABP therapy. Knowledge regarding IABP therapy is vital to safe, efficient patient care in the cardiothoracic intensive care unit (ICU) and should be so regarded by everybody involved. Lewis, Ward, and Courtney conducted a study in 2009 regarding IABP in heart failure management and they concluded that to achieve the best possible outcome for a patient managed with IABP, nursing and medical staff required specialized skills. Nurses play a critical role in patient monitoring and assessment in ICU. Moreover, critical care nurses are expected to manage IABP therapy. Nurses should assess changes in patients' condition which require knowledge of the cardiovascular system, therapeutic effects of IABP, and potential adverse events. ${ }^{[3]}$ This reveals that nursing care involves the care of the pump as well as assessing the patient from a cardiovascular and hemodynamic perspective. It is there for important that the critical nurse must have the knowledge to manage IABP therapy in a safe and therapeutic manner.

The nurse's role requires the operation of the IABP, while at the same time, the ability to deliver quality nursing care, knowledge of physiology, coordination of the principles of timing with hemodynamic effects, and skillful problem solving assure critical care nurse that they can effectively manage the IABP challenge. However, several studies reported that knowledge of the majority of critical care nurses tested was found to be insufficient. ${ }^{[4]}$ Moreover, there was no specific study conducted to assess and improves the knowledge and practice of staff nurses regarding the management of a patient with IABP, particularly, in that area considered important by the researcher. Thus, a quasi-experimental study was designed to assess the effect of planned teaching programme on knowledge and practice regarding the management of a patient with IABP among staff nurses working in ICU of the selected hospital. The study is conducted to explore the knowledge of the critical care nurse regarding the management of IABP therapy.

\section{Methodology}

The study was conducted in a multispecialty hospital. The rationale for selecting this setting was easy to transport, familiarity with the setting, administrative approval, cooperation, and availability of subject. The population selected for the present study was staff nurses. This study included 50 staff nurses working in ICU, who meet the inclusion criteria listed by the researcher. In this study, the sample consisted of 50 registered staff nurses working in intensive cardiac care unit of the selected hospital who were available during the period of data collection. The sampling technique used in this study was non-probability convenient sampling. Non-probability sampling entails the selection of most readily available individuals as a subject in the study, it represents typical conditions and researchers knowledge about his population and its elements can be used to hand pick cases. ${ }^{[5]}$

One group pre-test post-test design has been used to find the efficacy of the planned teaching programme on care of the patient on IABP among staff nurses with selected demographic variables. A pre-test was administered on day 1 by means of structured questionnaire depicted as 1 and then planned teaching programme was also conducted on day 1 and depicted as X. A post-test was conducted on day 7 using the same structured questionnaire depicted as 2. Based on the objectives of the study, a structured knowledge questionnaire and self-reported checklist based on the practice were prepared to evaluate the knowledge and practice of staff nurses before and after planned teaching programme. The knowledge questionnaire consisted of 15 close ended-multiple choice questions. Every correct response was given one. The maximum score on the knowledge questionnaire was 15 . Knowledge was graded from poor knowledge to excellent knowledge based on scores. Study design questionnaire defined as: 1 - The knowledge score of staff nurses before planned teaching programme; X-Treatment that is planned teaching programme; and 2 - the knowledge score of staff nurses after planned teaching programme.

\section{Statistical analysis}

The data were analyzed, using descriptive and inferential statistics based on objectives and hypothesis of the study. Analysis and comparison of knowledge scores and practice scores were performed using paired $t$-test. Association of knowledge and practice score with selected demographic variables was performed using ANOVA.

\section{REsULTS}

\section{Distribution of staff nurses on the basis of demographic} data educational qualifications

Table 1 represents data related to educational qualification of staff nurses, a maximum number of staff nurses that are

Table 1: Distribution of staff nurses according to their demographic data Educational qualifications

\begin{tabular}{lc}
\hline Demographic data & Frequency (\%) \\
\cline { 1 - 1 } Educational qualification & \\
\hline GNM & $5(10.0)$ \\
Post B. Sc. Nursing & $1(2.0)$ \\
Basic B. Sc. Nursing & $44(88.0)$ \\
MSc Nursing & $0(0)$ \\
Total & $50(100)$ \\
\hline
\end{tabular}

GNM: General nursing and midwifery 
Table 2: Assessment of knowledge regarding cardiovascular system among staff nurses

\begin{tabular}{llcc}
\hline Qn. No & Knowledge regarding the cardiovascular system & Pre-test F (\%) & Post-test F (\%) \\
\hline Q1 & What do you mean by cardiac cycle & $13(26)$ & $37(74)$ \\
Q2 & What is the function of the heart & $43(86)$ & $50(100)$ \\
Q3 & What do you mean by coronary circulation & $8(16)$ & $35(70)$ \\
Q4 & When IABP insertion is done & $22(44)$ & $50(100)$ \\
\hline
\end{tabular}

IABP: Intra-aortic balloon pump

44 (88\%) completed Basic BSc Nursing Course. 5 (10\%) staff nurses had completed their general nursing and midwifery. Only $1(2 \%)$ staff nurse had done Post Basic BSc Nursing. None of the staff nurses are postgraduated.

\section{Assessment of knowledge regarding cardiovascular system among staff nurses}

Table 2 indicates the analysis of data related to the knowledge regarding the cardiovascular system among staff nurses. Only $13(26 \%)$ of staff nurses were knowing about cardiac cycle before planned teaching programme while in post-test there was an improvement in the knowledge 37 (74\%). Maximum number $43(86 \%)$ of staff nurses knew about the function of the heart in the pre-test, but after planned teaching programme, all $50(100 \%)$ staff nurses were aware about the function of the heart. Minimum number $8(16 \%)$ of the staff nurses aware about the meaning of coronary circulation in the pretest, whereas in post-test the numbers jumped into $35(70 \%)$. Regarding knowledge of when IABP insertion to be done, only $22(44 \%)$ staff nurses had knowledge in the pre-test while all $50(100 \%)$ staff nurses were aware of it in post-test.

\section{Assessment of data of knowledge regarding IABP among staff nurses}

Maximum number $30(60 \%)$ of staff nurses were familiar with the full form of IABP in the pre-test. After planned teaching programme, all $50(100 \%)$ staff nurses were became aware of it. Minimum of $4(8 \%)$ of the staff nurses had knowledge regarding the principle of IABP before planned teaching programme, whereas in post-test the numbers increased to $36(72 \%)$. Furthermore, very few 7 (14\%) of the staff nurses were able to recognize when IABP is contraindicated in the pre-test, wherein post-test the numbers jumped to $41(82 \%)$. Only 17 (34\%) of staff nurses were knowledgeable about the indication of IABP insertion in the pre-test, but 43 (86\%) staff nurses were know about it in the posttest.

\section{Assessment of data of knowledge regarding component and insertion of IABP among staff nurses}

Nearly $25(50 \%)$ staff nurses properly identified the site of insertion of IABP in the pre-test, but after planned teaching programme, all $50(100 \%)$ staff nurses were aware of it. Only $2(4 \%)$ of the staff nurses knew the importance of gas reservoir in IABP as well as how to determine the size of IABP catheters in the pre-test, whereas in the post-test, 38 (76\%) and $41(82 \%)$, respectively, were aware of it, which shows significant improvement. Furthermore, very few $6(14 \%)$ of the staff nurses were able to know how to conform the position of IABP in the pre-test, whereas in the post-test $43(86 \%)$ staff
Table 3: Assessment of knowledge regarding IABP among Staff nurses

\begin{tabular}{llcc}
\hline $\begin{array}{l}\text { Qn. } \\
\text { No }\end{array}$ & Knowledge related to IABP & $\begin{array}{c}\text { Pre-test } \\
\text { F (\%) }\end{array}$ & $\begin{array}{c}\text { Post-test } \\
\text { F (\%) }\end{array}$ \\
\hline Q5 & What is the full form of IABP & $30(60)$ & $50(100)$ \\
Q6 & When IABP is indicated & $17(34)$ & $43(86)$ \\
Q7 & When IABP is contra indicated & $7(14)$ & $41(82)$ \\
Q8 & What is the principle of IABP & $4(8)$ & $36(72)$ \\
\hline
\end{tabular}

IABP: Intra-aortic balloon pump

nurses were able to know the method of conformation of IABP position after insertion.

Regarding knowledge of which gas is used in the gas reservoir of IABP, maximum 37 (74\%) staff nurses were marked it correct in the pre-test, but all $50(100 \%)$ staff nurses were aware of it in the post-test [Tables 3 and 4].

\section{Comparison of mean of pre- and post-test scores of knowledge}

Table 5 deals with the analysis of the pre-test and post-test knowledge regarding the management of the patient with IABP among staff nurses working in selected hospitals. Before calculating the $t$-value null hypothesis ( $\mathrm{H} 01)$ and alternate hypothesis (H1) was stated. The two tailed $t$-value for 0.05 level of significance was 2.01 for the degree of freedom $(\mathrm{df})=49$. The calculated $t$-value was found to be 31.76 for knowledge. As the calculated $t$-value is greater than the table $t$-value 2.01 at 0.05 level of significance with the degrees of freedom being 49, so null hypothesis (H01) which was "There will be no significant difference in the pre-test and post-test knowledge score regarding management of patient with IABP among staff nurses working in ICU after planned teaching programme" is rejected and alternate hypothesis (H1) is accepted. This shows that there is a statistically significant difference in the mean of pre- and post-test knowledge of the sample at 0.05 significant levels. These results support the effectiveness of planned teaching programme in the improvement of knowledge score regarding IABP among staff nurses working in a selected hospital.

\section{Comparison of pre- and post-score of reported practices}

Table 6 deals with the analysis of the pre-test and posttest. Practices regarding the management of a patient with IABP among staff nurses working in selected hospitals. Before calculating the $t$-value, null hypothesis (H02) and alternate hypothesis (H2) were stated. The two-tailed $t$-value for 0.05 level of significance was 2.01 for the degree of freedom $(\mathrm{df})=49$. 
Table 4: Assessment of data of knowledge regarding component and insertion of IABP among staff nurses

\begin{tabular}{llcc}
\hline Qn. no. & Knowledge regarding component and insertion of IABP & Pre-test F (\%) & Post-test F (\%) \\
\hline Q9 & How to determine size of IABP catheters & $2(4)$ & $41(82)$ \\
Q10 & What is the site of insertion of IABP & $6(50)$ & $50(100)$ \\
Q11 & How you will conform the position of IABP & $37(74)$ & $43(86)$ \\
Q12 & Which gas is used in the gas reservoir of IABP & $2(4)$ & $50(100)$ \\
Q13 & What is the importance of the gas reservoir in IABP & $38(76)$ \\
\hline
\end{tabular}

IABP: Intra-aortic balloon pump

Table 5: Comparison of pre- and post-test mean of knowledge

\begin{tabular}{lccccc}
\hline $\begin{array}{l}\text { Knowledge } \\
\text { comparison }\end{array}$ & Mean \pm SD & MD & SEMD & $\boldsymbol{t}$ value & $\boldsymbol{P}$ value \\
\hline $\begin{array}{l}\text { Pre-test } \\
\text { Post-test }\end{array}$ & $\begin{array}{c}4.60 \pm 2.13 \\
13.02 \pm 1.22\end{array}$ & 8.42 & 0.27 & 31.76 & 0.05 \\
\hline
\end{tabular}

SD: Standard deviation, MD: Mean of the difference, SEMD: Standard error of the mean difference

Table 6: Comparison of pre and post mean of practice

\begin{tabular}{lccccc}
\hline $\begin{array}{l}\text { Practice } \\
\text { comparison }\end{array}$ & Mean \pm SD & MD & SEMD & $\boldsymbol{t}$ value & $\boldsymbol{P}$ value \\
\hline $\begin{array}{l}\text { Pre-test } \\
\text { Post-test }\end{array}$ & $6.62 \pm 2.13$ & 8.38 & 0.302 & 27.7 & 0.05 \\
\hline
\end{tabular}

SD: Standard deviation, MD: Mean of the difference, SEMD: Standard error of the mean difference

The calculated $t$-value was found to be 27.77 for practice. As the calculated $t$-value is greater than the table $t$-value 2.01 at 0.05 level of significance with the degrees of freedom being 49, so null hypothesis ( $\mathrm{H} 02$ ) which was "There will be no significant change in practice score of staff nurses regarding the management of patient with IABP after planned teaching programme" is rejected and alternate hypothesis (H2) is accepted. This shows that there is a statistically significant difference in the mean of pre- and post-test practices of the sample at 0.05 significant levels. Hence, it proves that planned teaching programme is effective in improving practices regarding IABP among staff nurses working in selected hospitals.

\section{Evaluation of the effectiveness of planned teaching programme}

Part-A - Comparison of the mean of pre- and post-test scores of knowledge. The calculated $t$-value was found to be 31.76 for knowledge and the calculated $t$-value was greater than the table $t$-value 2.01 at 0.05 level of significance with the degrees of freedom being 49, so null hypothesis (H01) is rejected and alternate hypothesis (H1) is accepted. This shows that there is a statistically significant difference in the mean of pre- and post-test knowledge of the sample at 0.05 significant levels.

Part-B - Comparison of mean of pre- and post-test scores of reported practices. The calculated $t$-value was found to be 27.77 for practice and the calculated $t$-value was greater than the table $t$-value 2.01 at 0.05 level of significance with the degrees of freedom being 49, so null hypotheses (H02) is rejected and alternate hypothesis (H2) is accepted. Hence, it proves that planned teaching programme is effective in improving knowledge and practices regarding the management of a patient with IABP among staff nurses working in selected hospitals.

\section{Discussion}

The findings of the study were discussed with reference to the objectives and with the findings of the other studies in this section. The study revealed that most nurses had poor knowledge and practice related to IABP before teaching program which has been improved after also a positive correlation was found between knowledge and practice scores of the study subjects. They concluded empowerment of critical care nurses knowledge and practice would have a positive impact on their knowledge and performance.

Maneesha Gaikwad and Rupali Salvi conducted a quasiexperimental study to assess the effectiveness of planned teaching programme on knowledge and practices regarding the use of IABP among staff nurses working in critical care unit in selected hospitals of in Pune city. ${ }^{[6]}$ The researcher adopted a quantitative approach and selected 100 samples by non-probability purposive sampling technique.

The tool comprises structured questionnaire for knowledge and observation checklist for practice. The pre-test was conducted, and planned teaching programme were administered immediately after pre-test, the post-test was conducted 1 week later of pre-test with the same questionnaire. The data obtained were analyzed using descriptive and inferential statistics. In pre-test, the sampled staff nurses were having poor knowledge and practice regarding the management of a patient with IABP, and in post-test, the sample subject had an improved knowledge. In relation to the planned teaching programme, the paired $t$-test shows that the teaching program was statistically significant at $P<0.0001$ level. Those data proved that the knowledge of staff nurses had been markedly increased after the administration of planned teaching programme.

In this study, the calculated $t$-value was found to be 31.76 for knowledge and it was greater than the table $t$-value 2.01 at 0.05 level, and for practice, the calculated $t$-value was found to be 27.77, which was greater than the table $t$-value 2.01 at 0.05 level of significance. Hence, it was concluded that the planned teaching programme was significantly effective.

\section{Conclusion}

This study has helped to assess the knowledge and practice of staff nurse regarding the management of a patient with IABP. 
Knowledge and practices of staff nurses were inadequate before the administration of planned teaching programme. The knowledge and practice level of staff nurses in the post-test was significantly increased than the pre-test score. The findings of the study proved that teaching through planned teaching programme method was effective to improve the knowledge and practice of the staff nurses. This study reveals that it is important to have regular in service education programs for nurses to improve their knowledge and practical skills while caring the patient, to achieve quality care as well as prevent complications associated with IABP.

\section{RefEREnCeS}

1. Roger VL. Heart disease and stroke statistics. American heart association. Circulation 2011;123:e18-209.

2. Nursing-Interpreting Intra-aortic Balloon Pump Waveforms. Vol. 39.
Philadelphia, PA: Spring: Lippincott Williams and Wilkins Publishers; 2012. p. 9-10

3. Lewis SM, Heitkemper MM, Dirksen SR. Medical Surgical Nursing. $6^{\text {th }}$ ed. America: Mosby Publishers; 2000.

4. Alymahgoubl A, Hafezl AIA. Magnet work environment at military hospitals as perceived by registered nurses in KSA. IOSR J Nurs Health Sci 2017;6:54-62.

5. Sharma SK. Nursing Research and Statistics. $1^{\text {st }}$ ed. Haryana: Elsevier Publication; 2011. p. 81-2, 177-78.

6. Thite S, Gaikwad M, Salvi R. Knowledge and practice regarding management of patient with IABP among staff nurses. Int J Appl Res 2018; 4:140-6.

How to cite this article: Rasaria S, Sawant S. A Quasi-experimental Study to Assess the Effect of Planned Teaching Programme on Knowledge and Practice Regarding Management of Patient with Intra-Aortic Balloon Pump among Staff Nurses Working in Intensive Care Unit of Selected Hospital. Int J Nurs Med Invest. 2019;4(2):23-27 